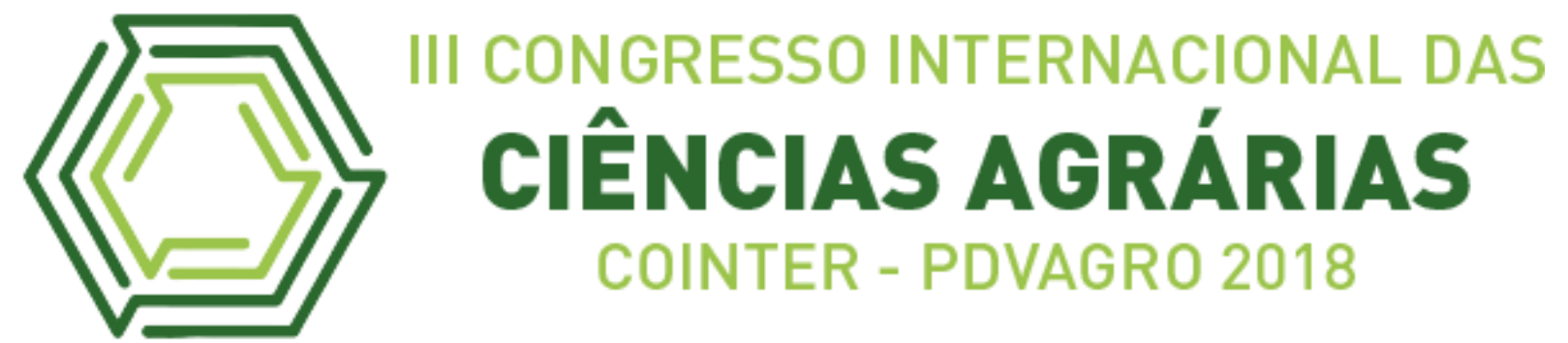

\title{
CONJUNTURA DO MERCADO DO CACAU NO ESTADO DO PARÁ: ASPECTOS NACIONAIS E REGIONAIS
}

\section{COCOA MARKET SETTING IN THE STATE OF PARÁ: NATIONAL AND REGIONAL ASPECTS}

\author{
Apresentação: Pôster
}

Ricardo Falesi Palha de Moraes Bittencourt ${ }^{1}$; Erika da Silva Chagas ${ }^{2}$; Camila Gurjão da Costa $^{3}$; Eloyza Marye Leão Cardoso ${ }^{4}$; Hercília Samara Cardoso da Costa ${ }^{5}$

\section{DOI: https://doi.org/10.31692/2526-7701.IIICOINTERPDVAGRO.2018.00393}

\section{Introdução}

O cacau é uma planta da família Sterculiaceae, produzida nas regiões de florestas tropicais do planeta, tendo como provável origem a Bacia Amazônica. Segundo a CEPLAC (Comissão Executiva do Plano da Lavoura Cacaueira), quando os primeiros colonizadores espanhóis chegaram à América, o cacau já era cultivado pelos índios, principalmente os Astecas, no México, e os Maias, na América Central, onde o seu cultivo estava associado à religiosidade, fato que provavelmente influenciou o botânico sueco Carolus Linneu (17071778), a denominar a planta de Theobroma cacao, cujo se traduz como "manjar dos deuses". O cacaueiro migrou tanto para o leste quanto para o norte e oeste do planeta avançando nas fronteiras climáticas das regiões equatoriais e tropicais. Para o leste, o tipo denominado "forasteiro" partiu inicialmente do Estado do Pará para o Estado da Bahia (BRANDÃO, 2008).

O cacau foi ganhando importância econômica com a expansão do consumo de chocolate por todo o mundo. O primeiro país produtor e fornecedor de cacau para os demais países foi o México. No século XVII, o México exportava cacau para a Espanha que desenvolveu a tecnologia para processamento das amêndoas de cacau (WICKIZER, 1951) que era apreciado pela família real e pelos nobres.

\footnotetext{
${ }^{1}$ Graduando em Agronomia, Universidade Federal Rural da Amazônia, ricardofalesibitten@gmail.com

${ }^{2}$ Graduanda em Agronomia, Universidade Federal Rural da Amazônia, erikachagas8@gmail.com.

${ }^{3}$ Graduanda em Agronomia, Universidade Federal Rural da Amazônia, gurj.mila@gmail.com.

${ }^{4}$ Graduanda em Agronomia, Universidade Federal Rural da Amazônia, eloyzacardoso2@gmail.com.

${ }^{5}$ Mestranda em Agronomia, Universidade Federal Rural da Amazônia, herciliacosta23@gmail.com.
} 
Segundo Paraiso (1987) o cultivo do cacau no Brasil começou, oficialmente, em 1679 com a Carta Régia, que autorizava os colonizadores a plantá-lo em suas terras. Atualmente, o Brasil produz apenas $4 \%$ do cacau consumido no mundo, estando na $7^{\text {a }}$ posição do ranking mundial, de acordo com dados da AIPC (Associação Nacional das Industrias Processadoras de Cacau). No topo do ranking de produção nacional está o estado do Pará, que produziu, em 2016, 117 mil toneladas de cacau, superando a produção do estado da Bahia, de acordo com o IBGE. A cadeia do cacau do Estado do Pará apresenta condições que lhe asseguram alta competitividade no mercado internacional, pois atende às exigências dos consumidores por produtos livres de agrotóxicos (MENDES \& LIMA, 2011).

Apesar da amêndoa do cacau ser o produto de maior importância econômica, do fruto do cacaueiro é possível ainda extrair outros subprodutos. Já é realidade a industrialização do suco de cacau, a fabricação de doces e geleias, de bebidas finas e destilados, a partir da extração da sua polpa. A casca do fruto também pode ter aproveitamento econômico, na alimentação de bovinos, suínos, aves e até peixes. A casca do fruto do cacaueiro pode ainda ser utilizada na produção de biogás e biofertilizante. A partir de estudo acerca da importância econômica da produção do cacau para o estado do Pará e para o Brasil, o presente estudo objetivou analisar a evolução do mercado da cacauicultura em âmbito nacional e regional com ênfase para o estado do Pará, nos anos de 2002 a 2017.

\section{Fundamentação Teórica}

A produção nacional de cacau teve uma queda, o maior produtor de cacau era o estado da Bahia, porém no ano de 2017 o estado do Pará passou a ser o maior produtor (IBGE, 2017). Isto levou a uma queda na produção, a conjuntura interna desfavorável é devida a devastação causada pela doença conhecida como "vassoura de bruxa" nos cacauais brasileiros, especialmente no Sul da Bahia (ISAE/FGV, 2003).

Apesar disso, o cacau é um produto tradicional da agricultura brasileira, importante para a economia e tem apresentando um avanço na sua produção nos últimos anos, após um período prolongado de crise.

\section{Metodologia}

O seguinte trabalho foi elaborado com base no banco de dados obtidos junto ao site do 
Instituto Brasileiro de Geografia e Estatística (IBGE), disponíveis no Sistema IBGE de Recuperação Automática (SIDRA), onde foram extraídos dados acerca da produção de cacaueira no mercado nacional e regional. Para complementar, foram feitas uma revisão em literaturas acerca do tema abordado. Os dados analisados foram referentes aos anos de 2002 a 2017.

\section{Resultados e Discussões}

A cacauicultura nacional está distribuída principalmente entre os Estados do Pará e Bahia, sendo estes segundo dados do IBGE - PAM, responsáveis por 96\% da produção total. No período analisado (2002 a 2017), verifica-se que a área colhida aumentou ligeiramente até o ano de 2016, posteriormente houve uma queda acentuada que impactou também na produção nacional conforme ilustra a Figura 1. Esta queda pode ser explicada devido ao período de estiagem que afeta o Estado da Bahia desde 2015, ocasionando perda de produção e mortalidade de alguns plantios. É possível observar também, um incremento positivo na produção nacional no intervalo entre 2002 e 2015.

Figura 1: Produção e Área Colhida a nível nacional Fonte: IBGE, 2017

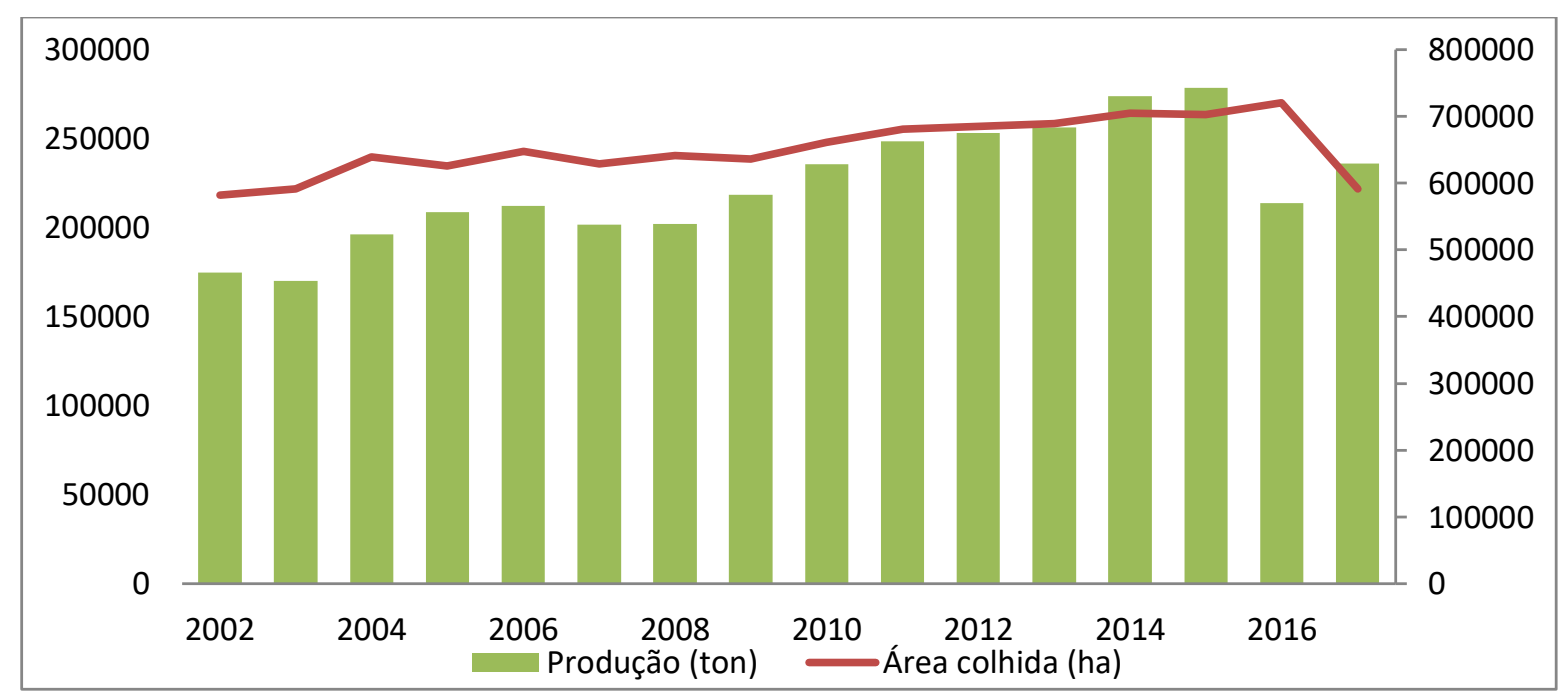

Com a queda na produção cacaueira no Estado da Bahia, o Pará assumiu em 2017 o papel de principal produtor nacional sendo responsável por praticamente metade da produção $(49,34 \%)$ seguido pela Bahia $(45,06 \%)$. 


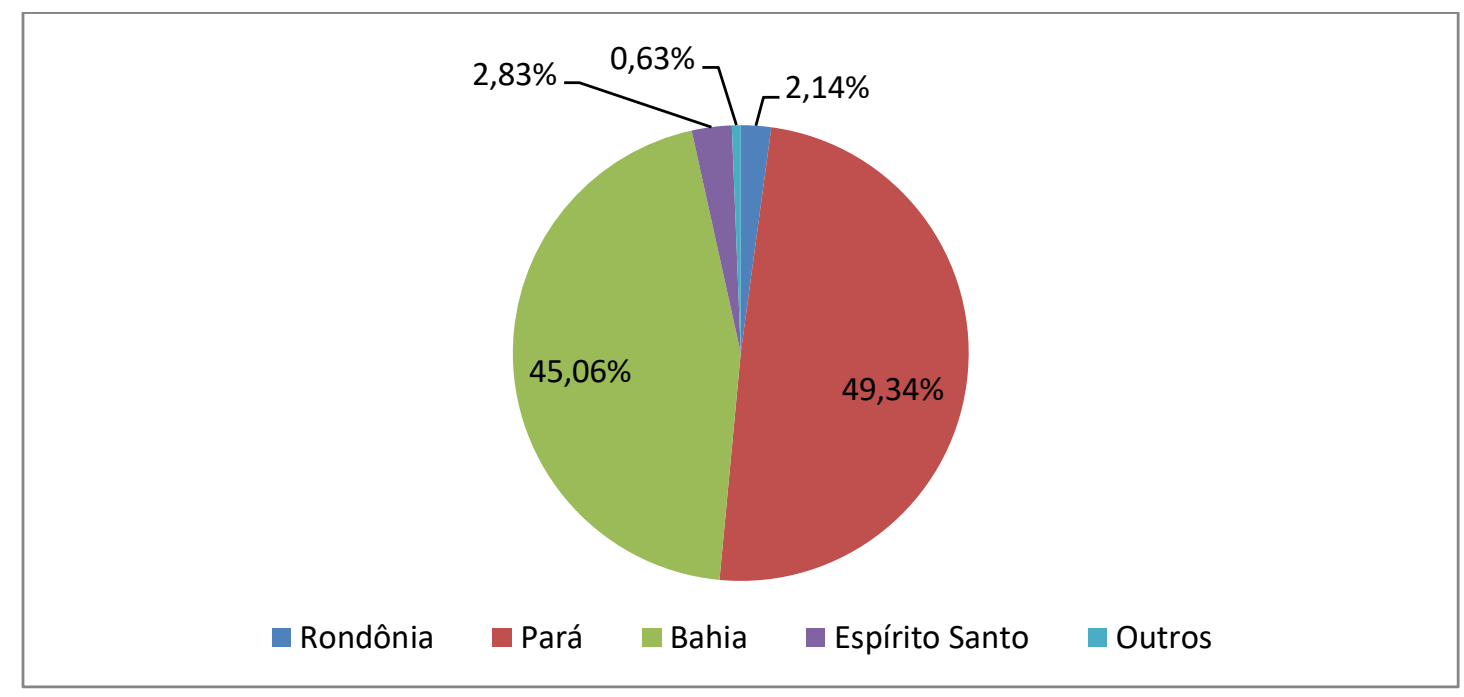

A perspectiva é de que o Estado do Pará mantenha a hegemonia produtiva desta atividade visto que desde 2002 houve um aumento de aproximadamente 90 mil hectares na área plantada. A expansão desta atividade na região foi efetuada sob tutela da CEPLAC (SILVA NETO et al., 2001).

A Figura 3 mostra o comportamento da produção cacaueira no Estado do Pará. A cacauicultura paraense é caracterizada pela exploração realizada por pequenos produtores e seus incrementos em produção estão relacionados aos avanços tecnológicos como o desenvolvimento de materiais tolerantes, sobretudo ao fungo Crinipellis perniciosa, e com maior potencial produtivo.

Figura 3: Produção e Área Colhida a nível Regional Fonte: IBGE, 2017

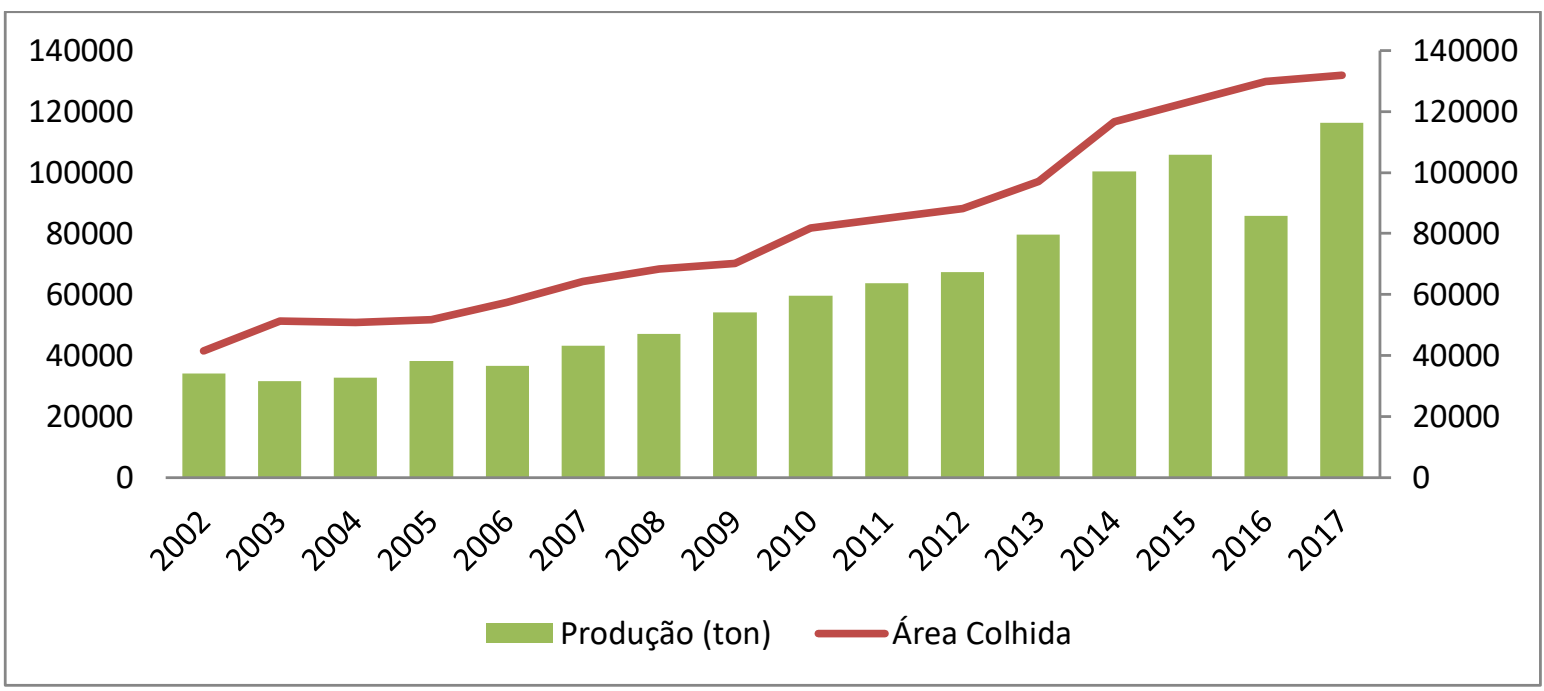


Os municípios Medicilândia, Uruará e Placas são os que mais contribuem para a alta produção no Estado, estes são responsáveis por 46938, 12265 e 7382 toneladas respectivamente (Figura 4). Vale ressaltar que, o município de Medicilândia possui é o maior produtor do país.

Figura 4: Contribuição dos municípios na produção do Estado do Pará. Fonte: IBGE, 2017

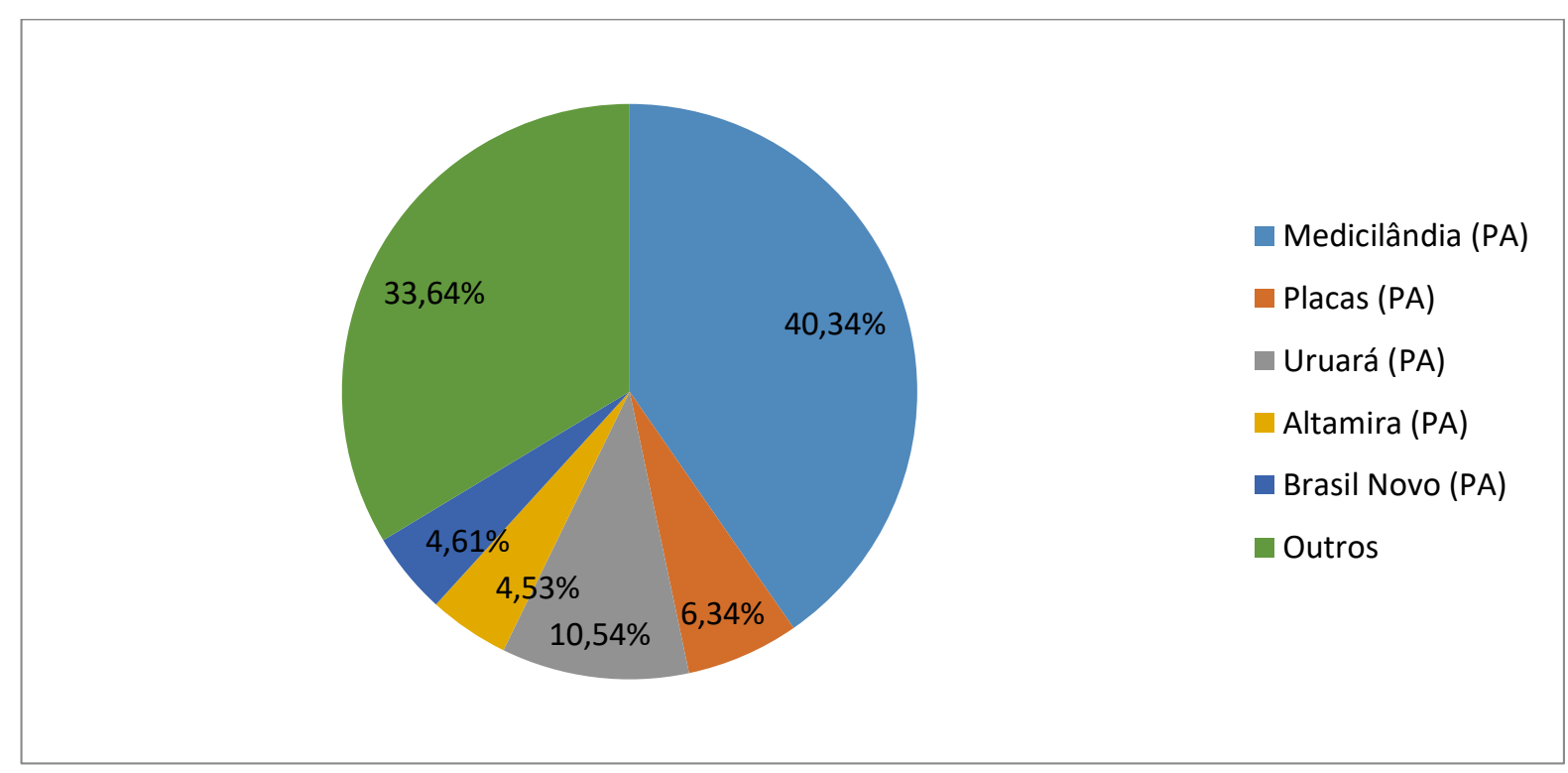

\section{Conclusões}

A produção de cacau encontra no Estado do Pará a possibilidade de se expandir em área e em produção, visto que a região dispõe de condições edafoclimáticas favoráveis e tecnologia adaptada. Esta expansão ocasionaria em impactos positivos para a economia, visando suprir as demandas do mercado e desta forma contribuindo na importância econômica e social desta atividade em âmbito nacional.

\section{Referências}

AIPC. Associação Nacional das Industrias Processadoras de Cacau. PLANO DE CRESCIMENTO DA CULTURA DO CACAU NO BRASIL, disponível em: < http://www.agricultura.gov.br/ >, acesso em: 23 de outubro de 2018.

BRANDÃO, J. R. A Cultura do Cacau em SAF: reflexões sobre a identificação de valoração de serviços ambientais e sócio econômica da Transamazônica. Belém:UFPA, 2008. (Monografia de conclusão de curso de especialização). 
CEPLAC. Comissão Executiva do Plano da Lavoura Cacaueira. CACAU HISTÓRIA E EVOLUÇÃO, disponível em < http://www.ceplac.gov.br/ >, acesso em: 22 de outubro de 2018.

HISTÓRIA DO CACAU. Disponível em: < http://mercadodocacau.com/cacau >, acesso em: 23 de outubro de 2018.

IBGE. Instituto Brasileiro de Geografia e Estatísticas. Levantamento Sistemático da Produção Agrícola (LSPA), 2016. Disponível em: < https://ibge.gov.br/ >, acesso em: 23 de outubro de 2018

MENDES, F. A. T.; LIMA, E. L. Perfil agroindustrial do processamento de amêndoas de cacau em pequena escala no Estado do Pará. SEBRAE/PA. 2011.

MORAES, M. C.; \& ALBUQUERQUE, A. P. Previsão para o preço futuro do cacau através de uma série univariada de tempo: uma abordagem utilizando o método ARIMA. In: 44th Congress, July 23-27, 2006, Fortaleza, Cear $\tilde{A}_{\mathbf{i}}$, Brazil. Sociedade Brasileira de Economia, Administracao e Sociologia Rural (SOBER), 2006.

ISAE/FGV. Cacau: Pontencialidades Regionais e Estudo de Viabilidade Econômica. Manaus: Suframa, 2003.

PARAISO, M. H. B. (1987). Os índios de Olivença e a zona de veraneio dos coronéis de cacau da Bahia. Revista de Antropologia, 79-109.

SILVA NETO, P. J.; MATOS, P. G. G.; MARTINS, A. C de S.; SILVA, A. de P. Sistema de produção de cacau para a Amazônia brasileira. CEPLAC, Belém, 125 p. 2001.

WICKIZER, V. D. Coffee, Tea, and Cocoa, An Economic and Political Analysis. Edited by F. R. Institute, Food, Agriculture, and World War II. Stanford, California, USA: Stanford University Press. 1951. 